\title{
3rd ICTs and Society Meeting; Paper Session - Theorizing the Internet; Paper 5: Shaping the third mode of human existence on the Internet
}

\author{
László Ropolyi
}

Department of History and Philosophy of Science

Eötvös University, Budapest, Hungary

ropolyi@elte.hu

\begin{abstract}
We propose to build up a philosophy of the Internet instead of building up its scientific theory. Our philosophy of the Internet includes several components of the philosophy of technology, information, communication, culture and organization because we use four different coexisting contexts for the better understanding of the nature of the Internet: the technological, the communication, the cultural and the organism ones. This philosophy of the Internet shows that the Internet is the sphere of a new mode of human existence, basically independent from, but built on and coexisting with the former (natural and societal) spheres of existence, and created by the late-modern humans.
\end{abstract}

Keywords: Internet, technology, communication, culture, organism, nature, society, web-life, human existence

The presentation has two parts. First a philosophical analysis of the nature of the Internet will be presented. Second this will be associated with the human nature to show a possible role of the Internet in the formation of the future of mankind.

As it is well known the Internet is a complex being and we have no widely accepted theoretical or philosophical description of its characteristics and nature. The empirical studies on the Internet ${ }^{1}$ cover an extremely wide area of experiences - so it is not possible to create a scientific theory of the Internet which would be similar to a normal scientific discipline. Moreover, because of the lack of the agreement about a well-defined group of relevant experiences we neither can create inter- or multidisciplinary theory. In this situation we propose to create a philosophy of the Internet instead of building up its scientific theory. ${ }^{2}$ The philosophical analyses are sensible and effective enough to consider the coexisting funda-

\footnotetext{
${ }^{1}$ See e.g. (Wellman \& Haythornthwaite, 2002).

${ }^{2}$ See (Ropolyi, 2007).
}

mentally different experiences, approaches, ideas on the Internet and can try to discover their common essence or features.

The philosophy of the Internet would be a philosophical view, so it would have many forms, variants with somehow different systems of values and worldviews. ${ }^{3}$ In this paper four interrelated contexts will be suggested for description of the most fundamental characteristics and the very nature of the Internet. Our motivation comes from an Aristotelian description of the nature of things. In the Aristotelian philosophy the proper understanding of the nature of a thing we have to discover its four causes - actually answer the questions of what, how, what from and why a given thing exists. Applying this view to the understanding of the real nature of the Internet we would propose four coexisting different contexts for its complex description: the technological, the

\footnotetext{
${ }^{3}$ Several philosophical analyses of the Internet are available - however, not under the name „philosophy of the Internet" and their main goal usually to study certain philosophical problems instead of a detailed description of the Internet -, for example: (Dreyfus, 2001).
} 
communication, the cultural and the organism ones. In this way our philosophy of the Internet includes several components of the philosophy of technology, information, communication, culture and organization. The very short summaries of the chapters of this philosophy of the Internet ${ }^{4}$ are the followings:

\section{Technological context}

Technology is a specific form or aspect of human agency that yields to - an imperfect realization of the human control over a technological situation, i.e. the technological situation is not governed to an end by natural constraints but by specific human aims. Every element of the human world and even the world itself are created by technologies. The Internet can be considered as a kind of information technology. Characterization of information technology is based on an understanding of the concept of 'information' and leads to emphasizing of the role of 'virtuality' and 'openness' in every relevant situation. For a deeper understanding of the consequences of information technology a hermeneutic approach to the concept of information is very fruitful: every interpreted being can be considered as information. From this position the information technology is a "hermeneutical industry", where the production is performed by interpretation in the individual human minds. From technical point of view the Internet is an intentionally created and maintained artificial, virtual sphere that is based on networked computers and individual human interpretation praxes.

\section{Communication context}

Communication can be considered as a technology of community building, because in the process of communication we want to share our mental states, views, experiences, etc. with each other, and in this way to create a community between us. Communication technology is a specific form or aspect of human agency which yields to - an imperfect realization of the human control over a communication technological situation, i.e. the communication situation is not governed to an

\footnotetext{
${ }^{4}$ More details see (Ropolyi, 2006)
}

end by natural constraints but by specific human aims: to build up a specific community. Every element of the human communities and the community itself are created by communication. Communication via Internet is a technology of building up virtual, open, extended communities. A deeper understanding of the communication via Internet is based on a communication situation analysis, including considerations on the active role of the media, the specificity of computers as communication machine, and the possibility of the highest level of individual control of the situation. From communication point of view the Internet is an intentionally created and maintained network of artificial, extended, virtual communities which are based on networked communication machines and individual human control over the communication situations.

\section{Cultural context}

Culture is a network of values realized in coexisting human communities, the "world" of communities. It expresses and forms the fundamental contents of the human existence. Cultural praxis can be considered as a technology of building up human worlds or human nature. The Internet can be considered as a universal medium of culture, which can accommodate, represent and maintain (as a new, artificial "brain") the whole human culture. Traditional cultural practice creates a public social world from natural beings by reevaluation of natural conditions, but the "cybercultural' praxis of the Internet creates private individual worlds of netizens from the social system by re-evaluation of social values. Netizen is a citizen of three worlds: natural, societal, and the net. From cultural point of view the Internet is an intentionally created and maintained network of artificial, extended, virtual communities of the late-modern humans on which cybercultural networks of values are realized.

\section{Organism context}

An organism is a complex being with given identity, integrity, reproducibility and organizing principles. The Internet can be considered as a superorganism, i.e. an organism of organisms consists of technical systems, com- 
municative networks, and interwoven worlds. The Internet is a postmodern superorganism imbued with the values plurality, virtuality, fragmentality, individuality, against power, and included modernity. From organism point of view the Internet is an artificial superorganism consisting of systems, networks and worlds, created and maintained by the late-modern humans driven to the wish for an independent, free, own "home".

\section{The Internet}

The Internet is the medium (or realm, or sphere) of a new mode of human existence, basically independent from, but built on, and coexisting with the former (natural and socie- tal) spheres of existence, and created by the late-modern humans.

\section{The third mode of human existence}

From this position we can understand the significance of the Internet for the human conditions. Before the Internet use - as we know from Kant - there were two modes of human existence: the natural and the social. Now a new mode becomes possible: the third mode of human existence is the web-life. Nowadays a more complex world is emerging in which the natural, the social and the weblife are simultaneously present. The 'human essence' has moving from the social to the web-life. A new period of human history has started.

\section{References}

Dreyfus, H. L. (2001). On the Internet. London: Routledge.

Ropolyi, L. (2006). Az Internet természete. Internetfilozófiai értekezés (The Nature of the Internet. Discourse on the Philosophy of the Internet. - in Hungarian). Budapest: Typotex.

Ropolyi, L. (2007). Shaping the philosophy of the Internet. (pp. 329-334), In: S. Kaneva, (Ed.). Philosophy Bridging Civilizations and Cultures, Sofia: IPhR - BAS.

Wellman, B. \& Haythornthwaite, C. (2002) (Eds.). The Internet in Everyday Life. Malden/Oxford/Carlton: Blackwell.

\section{About the Author}

László Ropolyi

He studied physics and philosophy at the Eötvös University, Budapest. Now he is a lecturer in history and philosophy of science at the same university. His research fields include: history and philosophy of science, hermeneutics as philosophy of science, social constructivism, communication studies, and philosophy of the Internet. 